\title{
Secreto médico e intimidad vs. protección del interés superior del menor: comentario a la sentencia 4/2018 de 10 de enero de la Sala Segunda del Tribunal Supremo
}

\author{
Medical Secret and Privacy v. Protection of the Best Interest of \\ the Child: Commentary on Judgment 4/2018 of January 10th \\ of the Second Hall of the Spanish Supreme Court
}

\author{
Alberto Hidalgo CeREZO \\ UNED Madrid \\ a.hidalgo@icam.es
}

\begin{abstract}
Resumen: En materia de intimidad y protección de datos relativos a la salud del paciente, el Tribunal Supremo venía manteniendo una sólida línea jurisprudencial, en la cual se reflejaba de forma clara la exigencia a los profesionales sanitarios en la salvaguarda del secreto profesional y la protección de los datos del paciente. Resulta llamativa la sentencia de análisis, de 10 de enero de 2018 de la Sala Segunda del Tribunal Supremo, por rebajar la condena a una enfermera que accedió sistemáticamente desde 2011 hasta 2015 a la historia clínica de su ex yerno y su nueva pareja. Para ello, el Alto Tribunal concede relevancia al hecho de que la condenada manifestó reiteradamente actuar en defensa de sus nietos, de donde infiere que se encontraba en un estado de obcecación. Esta consideración podría abrir una vía, tal vez poco afortunada, al acceso indebido de los profesionales a los datos sanitarios de ex parientes e incluso de terceras personas, prevaliéndose de su condición, sin que se tenga en cuenta no solo la gravedad de la vulneración del derecho a la intimidad del paciente, sino que el autor de tal agresión es además un profesional que conoce perfectamente la gravedad de la misma.
\end{abstract}

Palabras clave: Secreto médico; intimidad; protección de datos; atenuantes; interés superior del menor.

\begin{abstract}
In terms of privacy and data protection related to the patient's health, the Spanish Supreme Court had maintained a solid jurisprudential line, which clearly reflected the requirement for health professionals in the safeguard of professional secrecy and the protection of patient's data. The Sentence of analysis, of January 10, 2018 of the Second Chamber of the Supreme Court, is striking for lowering the sentence to a nurse who accessed systematically from 2011 to 2015 to the medical history of his former son-in-law and his new partner. To this end, the High Court grants relevance to the fact that the convicted woman repeatedly stated that she was acting in defense of her grandchildren, from which she inferred that she was in a state of stubbornness. This consideration could open a way, perhaps unfortunate, to the illegitimate access of professionals to the health data of former relatives and even of other third parties, without taking into account not only the seriousness of the violation of the right to privacy of the patients, but also the fact that the author of such aggression is a professional perfectly aware its significance.
\end{abstract}

Keywords: Medical secret; privacy; data protection; extenuating circumstances; best interest of the child. 


\section{INTRODUCCIÓN: LA IMPORTANCIA DE LA INTIMIDAD DEL PACIENTE Y LA PROTECCIÓN DE LOS DATOS RELATIVOS A SU SALUD}

L a protección de datos de carácter personal encuentra cada vez mayor aceptación y sensibilidad en la sociedad del siglo XXI, siguiendo la estela de su desarrollo normativo a finales del siglo $\mathrm{XX}^{1}$. Su relevancia se ha visto reflejada en el importante desarrollo legislativo que ha experimentado tanto a nivel nacional como de derecho comunitario. En España, por mor de los arts. 18.1 y 18.4 de la Constitución, desarrollados a través de la Ley Orgánica de Protección de Datos (LOPD) y de su correspondiente Reglamento (RLOPD). En Europa aparecen también recogidos al máximo nivel, dado que así lo establece, en primer lugar, el artículo 16.1 del Tratado de Funcionamiento de la Unión Europea (TFUE), así como los artículos 7 y 8.1, de la Carta de los Derechos Fundamentales de la Unión Europea (CDFUE), de acuerdo a los cuales toda persona tiene derecho al respeto de su vida privada y familiar ${ }^{2}$ y a la protección de los datos de carácter personal que le conciernan ${ }^{3}$. También el nuevo Reglamento General de Protección de Datos (RGPD) 2016/6794 re-

1 La Constitución Portuguesa de 1976 es pionera en el reconocimiento al máximo nivel del derecho, entonces embrionario, a la protección de datos en su artículo 35 -posteriormente reformado en 1982 y 1989-. Dos años más tarde, y aunque no inserto propiamente en el cuerpo constitucional, vale la pena destacar su introducción por vía de Ley Federal (Bundesgesetz über den Schutz personenbezogener Daten), dentro de la particular configuración de derechos fundamentales en Austria, por el que se le reconoce rango constitucional (Verfassungsrang). Con posterioridad, otras constituciones de nuestro entorno cultural fueron incorporando referencias a la protección de datos. Así, la Constitución Finlandesa tras su reforma de 1980 en el art. 8; la Ley Fundamental de los Países bajos en 1983, o la Constitución de Suecia desde 1994. La Corte Costituzionale della Repubblica Italiana ha incorporado este diritto a la riservatezza -e alla protezione dei propri dati personali- a través de una interpretación expansiva de su art. 13, relativo a la libertad personal en conexión con el art. 2, que reconoce la inviolabilidad de los derechos del hombre. En parecidos términos, y también en clave de construcción doctrinal a través de la jurisprudencia del tribunal constitucional, el Bundesverfassungsgericht alemán también ha acudido a estos preceptos más genéricos como la inviolabilidad de la dignidad del ser humano (art. 1.1) y el libre desarrollo de la personalidad (art. 2.1) de la Grundgesetz für die Bundesrepublik Deutschland (Ley Fundamental para la República Federal de Alemania), dando un enclave constitucional al Informationelle Selbstbestimmung (derecho a la autodeterminación informativa) a partir de 1983.

2 PÉrez Luño, A., Derechos bumanos, Estado de Derecho y Constitución, Tecnos, Madrid, 2005, p. 327.

3 Garriga DomíngueZ, A., Nuevos retos para la protección de datos personales en la era del Big Data y de la computación ubicua, Dykinson, Madrid, 2015, pp. 80 y 81.

4 Reglamento (UE) 2016/679 del Parlamento Europeo y del Consejo, de 27 de abril de 2016, relativo a la protección de las personas físicas en lo que respecta al tratamiento de datos personales y a la libre circulación de estos datos y por el que se deroga la Directiva 95/46/CE (Reglamento general de protección de datos). Publicado en el DO L 119 de 4.5.2016. 
cuerda en su artículo 1.2 que: «El presente Reglamento protege los derechos y libertades fundamentales de las personas físicas y, en particular, su derecho a la protección de los datos personales ${ }^{5}$. A nivel internacional, queda reconocido en el art. 10.1 del Convenio de Oviedo sobre Derechos Humanos y Biomedicina de 1997, según el cual: «Toda persona tendrá derecho a que se respete su vida privada cuando se trate de informaciones relativas a su salud».

La jurisprudencia también ha avalado la importancia de esta especialidad. En España, son célebres las SSTC 290/20006 y 292/20007 , por haber configurado los fundamentos constitucionales de la misma en España (a este respecto, en nuestra doctrina destacan los análisis de DÍAZ REVORIO ${ }^{8}$ y CASTILLA BAREA $^{9}$ por su rigor y extensión) o, específicos de datos médicos, el Auto de

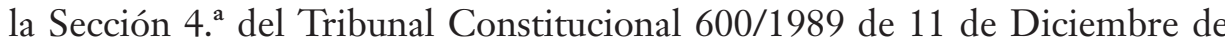
1989, y las sentencias del Tribunal Constitucional 70/2009, de 23 de marzo, y 159/2009, de 29 de junio. En el ámbito comunitario, destaca sobre todas la sentencia del Tribunal de Justicia (Gran Sala) de la Unión Europea de 6 de oc-

5 Hidalgo Cerezo, A., «Protección de datos de carácter personal relativos a la salud del paciente: fundamentos, protección a la intimidad y comentarios al nuevo Reglamento UE 2016/679», RDUNED, n. ${ }^{\circ}$ 19, pp. 715-744, <http://e-spacio.uned.es/fez/eserv/ bibliuned:RDUNED-2016-19-7230/pag_715.pdf>, 2016 (8 de abril de 2018).

6 Sentencia del Tribunal Constitucional 290/2000, de 30 de noviembre de 2000. Recursos de inconstitucionalidad acumulados 201/93, 219/93, 226/93 y 236/93.

7 Sentencia del Tribunal Constitucional 292/2000, de 30 de noviembre de 2000. Recurso de inconstitucionalidad 1463/2000.

8 Díaz Revorio, F.J., «Principios de la protección de datos: derecho de la información en la recogida de datos. Una perspectiva constitucional», en Troncoso ReIgada, A. (coord.), Comentario a la ley Orgánica de Protección de Datos de Carácter Personal, Thompson Civitas, Pamplona, 2010, pp. 433-454: «Lo que hoy denominamos derecho fundamental a la protección de datos personales, libertad informática, autodeterminación informativa o habeas data, es en el sistema español un derecho fundamental de creación jurisprudencial, pues el artículo 18.4 de la Constitución, que le sirve de sustento principal, establece en puridad un mandato al legislador ('La ley limitará el uso de la informática...') y no un derecho fundamental en sentido propio. El Tribunal Constitucional, siguiendo la estela del Bundesverfassungsgericht alemán [que en 1983 babía establecido la existencia de un derecho de autodeterminación informativa, derivado del derecho general a la personalidad del artículo 2 de la Ley Fundamental (...)]». Respecto a dicha sentencia, absolutamente de referencia en la materia, vid. DARANAS, M., «Sentencia de 15 de diciembre de 1983: Ley del Censo. Derecho de la Personalidad y Dignidad Humana», en Boletín de Furisprudencia Constitucional, Dirección de Estudios y Documentación del Congreso de los Diputados, tomo IV (Jurisprudencia Constitucional Extranjera), n. ${ }^{\circ} 33$, Madrid, 1984, pp. 126-170.

9 Castilla Barea, M., «Sentencias del Tribunal Constitucional 290/2000 y 292/2000, de 30 de noviembre de 2000 (Derecho a la libertad informática)», en MARTínEZ VÁZQUEZ DE CASTRO, L. y Escribano Tortajada, P. (coords.), Comentarios a las sentencias del Tribunal Constitucional en materia civil, Tirant lo Blanch, Valencia, 2016, pp. 1111-1217, incluyendo transcripción literal de la resolución. 
tubre de 2015, en el asunto C-362/14, más conocido como caso Safe Harbor ${ }^{10}$. En la misma, el Tribunal recuerda en su apartado 78: «el importante papel que cumple la protección de los datos personales en relación con el derecho fundamental al respeto de la vida privada». Con anterioridad, ya se vino pronunciando en esta línea garantista: «el tratamiento de datos personales, que puede vulnerar las libertades fundamentales $y$, en particular, el derecho al respeto de la vida privada, deben ser necesariamente interpretadas a la luz de los derechos fundamentales protegidos por la Carta». Este criterio viene siendo constante en el TJUE, como demuestran la sentencias de los casos Österreichischer Rundfunk ${ }^{11}$, Rijkeboer ${ }^{12}$, Google Spain $^{13}$, y Ryneš ${ }^{14}$, todas ellas coincidentes en cuanto a la relevancia y alcance de la protección de datos como derecho fundamental. La cuestión, dado el reconocimiento de estos derechos en la CDFUE, ha sido también abordada por el Tribunal Europeo de Derechos Humanos, del que, en apretada síntesis, podemos destacar las sentencias de 25 de febrero de 1997 (caso Z. contra Finlandia) y de 10 de octubre de 2006 (caso L.L. contra Francia), con idéntica perspectiva que las anteriores.

A mayor abundamiento, cuando nos referimos a la protección de datos relativos a la salud del paciente, nos encontramos ante una modalidad reforzada de los mismos, por ser especialmente sensibles. En efecto, esto se debe, en primer lugar, a su configuración legal en el art. 7.3 LOPD. Pero además, porque la enfermedad pone al paciente en una posición de debilidad, acudiendo a la asistencia sanitaria con la necesidad de restaurar su salud, para lo cual desvela a los profesionales información que en muchas ocasiones pertenece a su esfera más privada y que forma parte nuclear de su intimidad. Es en ese contexto donde se incardina el secreto médico.

10 Sentencia del Tribunal de Justicia de la Unión Europea de 6 de octubre de 2015 (Gran Sala). C-362/14: Maximillian Schrems contra Data Protection Commissioner.

11 Sentencia del Tribunal de Justicia de la Unión Europea de 20 de mayo de 2003. Casos acumulados: C-465/00, C-138/01 y C-139/01: Österreichischer Rundfunk. Apartado 68 de la resolución.

12 Sentencia del Tribunal de Justicia de la Unión Europea de 7 de mayo de 2009 (Sala Tercera). C-553/07: College van burgemeester en wethouders van Rotterdam contra M. E. E. Rijkeboer. Apartado 47 de la resolución.

13 Sentencia del Tribunal de Justicia de la Unión Europea de 13 de mayo de 2014 (Gran Sala). C-131/12: Google Spain, S.L. y Google Inc. contra Agencia Española de Protección de Datos (AEPD) y Mario Costeja González. Apartado 68 de la resolución.

14 Sentencia del Tribunal de Justicia de la Unión Europea de 13 de mayo de 2014 (Sala Cuarta). C-212/13: František Ryneš contra Úřad pro ochranu osobních údajü. Apartado 29 de la resolución. 
A este respecto, SERRANO GIL ${ }^{15}$ afirma que existen tres tipos de secreto: el natural, el prometido, y el confiado. Nos encontramos ante el último tipo, cualificado, porque existe una condición previa de guardarlo para la persona que obtiene la información. En este caso, debe secreto por razón de su profesión. Este autor considera, acertadamente, que: «En el secreto profesional (más riguroso que el natural o el prometido) existe un contrato bilateral, y en muchas ocasiones oneroso, que impone el deber de cumplir la obligación». Y profundiza detallando la importancia social del mismo: «se trata de un secreto confiado, mediante el cual el profesional se obliga a mantener ocultas todas aquellas confidencias que reciba en el ejercicio de su profesión. Es un pacto entre el cliente y el profesional siendo exigible, no solo por el interés del propio cliente, sino también por el bien social.»

Con el objetivo de mejorar la salvaguarda de esta información reservada, la Agencia Española de Protección de Datos, publicó un sencillo decálogo ${ }^{16}$ destinado a los profesionales sanitarios, a fin de concienciar sobre la importancia de esta cuestión. Sin embargo, dicho documento no es más que un resumen del Plan de Inspección Sectorial de Oficio Hospitales Públicos ${ }^{17}$, donde el referido organismo pone de manifiesto que es necesario realizar actuaciones de mejora en cuatro áreas: «la calidad y la confidencialidad de los datos conservados, la información ofrecida a los pacientes así como a los sujetos participantes en los ensayos clínicos, la obtención de los consentimientos en todos los casos en que este sea necesario, y el reforzamiento de las medidas de seguridad, potenciando con carácter general los mecanismos de control de acceso».

A la luz de lo anteriormente expuesto, resulta destacable la conexión que realiza TRONCOSO REIGADA entre los referidos arts. 18.1 y $18.4 \mathrm{CE}$ (derecho a la intimidad y protección de datos) y los arts. 15 y 43 CE: «Los datos de salud y la bistoria clinica tienen una enorme importancia porque son instrumentos necesarios para garantizar la asistencia sanitaria de las personas, y por tanto están intimamente vinculados al derecho a la vida-Art. 15 CE-y a la protección de la salud-Art. 43 CE-. La acumulación de datos sanitarios de los pacientes en las historias clínicas y su

15 Serrano Gil, A., «La enfermería y el secreto profesional», en Hidalgo Cerezo, A. (dir.), Los profesionales de enfermería ante la ley, Díaz de Santos, Madrid, 2018, pp. 99-100.

16 Agencia Española de Protección de Datos: «Decálogo de protección de datos para el personal sanitario y administrativo». <_http://www.agpd.es/portalwebAGPD/canaldocumentacion/publicaciones/common/Guias/2017/DecalogoPersonalSanitario.pdf>, 2017 (9 de abril de 2018).

17 Agencia Española de Protección de Datos: «Plan de Inspección Sectorial de Oficio Hospitales Públicos». <http://www.agpd.es/portalwebAGPD/canaldocumentacion/publicaciones/common/Guias/2017/PlanInspeccionHospitalesPublicos.pdf>, 2017 (9 de abril de 2018). 
correcta conservación son elementos necesarios para poder llevar un seguimiento del estado de salud de las personas» ${ }^{18}$. Para finalizar, resulta de obligada mención en nuestra doctrina ROMEO CASABONA: «Por tal motivo el secreto médico debe quedar protegido de forma general por la normativa que protege el derecho a la intimidad. Este derecho a la intimidad presenta múltiples facetas, algunas de las cuales afectan al ejercicio de la Medicina, como es el rechazo a toda intromisión no consentida en la vida privada, la no difusión de la información profesionalmente obtenida, la protección de los datos personales informatizados, etc» ${ }^{19}$.

Teniendo en cuenta este marco, podemos apreciar por qué resulta interesante la sentencia objeto de estudio. Con anterioridad, en casos similares, el Tribunal Supremo había protegido con celo el rigor exigible a los profesionales sanitarios en el cumplimiento de su deber de secreto. Así se desprende de las resoluciones que confrontaremos en el apartado cuarto de este trabajo con la sentencia objeto de estudio.

Esta garantía, que se exige a todo profesional sanitario debido a la clase de datos a la que tiene acceso por razón de su profesión, puede ser vista desde dos perspectivas. De un lado, desde el clásico deber de secreto por los motivos mencionados apenas unos párrafos atrás. Pero también, desde un prisma de exigencia, conectada a un conocimiento muy cualificado de la importancia de mantener la intimidad de los pacientes, mandato que, a sabiendas, desoyó la acusada, en lo que resulta un comportamiento muy reprochable y desleal que no puede caer en el olvido.

Pero la verdadera clave que hace a esta sentencia merecedora de análisis, es la importancia que se otorga a la versión sostenida por la acusada, según la cual el Tribunal Supremo considera que: «el acceso a los datos reservados, lo realizaba con el ánimo de tratar de proteger a dichos menores (sus nietos)》. La pregunta es obvia: ¿qué acciones llevó a cabo para tal defensa, tras aprehender la información privilegiada de las historias clínicas? ¿Qué resultado obtuvieron?

En la otra cara de la moneda quedan las víctimas, muy indefensas ante una sistemática y reiterada violación de su intimidad, sostenida en el tiempo

18 Troncoso Reigada, A., La protección de datos personales. En busca del equilibrio, Tirant lo Blanch, Valencia, 2010, p. 1099. Posteriormente, conecta todos ellos con otros derechos constitucionales, como el art. 27 (derecho a la educación) o el art. 35 (derecho al trabajo), explorando la transversalidad que despliegan tanto la protección de datos como el derecho a la salud.

19 Romeo Casabona, C.M., «La intimidad del paciente desde la perspectiva del secreto médico y del acceso a la historia clínica», DS: Derecho y salud, vol. 1, n. ${ }^{\circ} 1$ (1993), pp. 4-5. 
durante cuatro años. Además de lo anterior, desde este momento podemos afirmar que se ha infravalorado su daño moral por esta causa, fijado en 750 euros para cada una de ellas. Sentadas estas bases, a continuación abordamos el análisis de la sentencia de referencia, poniendo de relieve los hechos considerados probados por el Alto Tribunal.

\section{HECHOS PROBADOS DE LA SENTENCIA Y CRÍTICA A SU FORMULACIÓN}

El Tribunal Supremo comienza recogiendo, en su antecedente de hecho primero, los hechos probados contenidos en la sentencia objeto de recurso, dictada por la Sección Segunda de la Audiencia Provincial de Cáceres (APC) con fecha 5 de diciembre de 2016, rollo 24/2016. En la misma, se detalla que la acusada venía desarrollando su trabajo como enfermera de atención primaria, lo que le permitía acceder a una parte de los historiales clínicos de los pacientes del Servicio Extremeño de Salud. Afirma el Tribunal que: «aprovechando dicha circunstancia, accedió en más de un centenar de ocasiones» (desde principios de 2011 y hasta el año 2015) al historial clínico informatizado de su ex yerno y su nueva pareja, habida cuenta que aquel es el padre de los nietos de la acusada.

Quizá uno de los puntos clave por los que pasa de puntillas la fundamentación de la resolución, a pesar de la acertada aplicación de la agravante del art. $198 \mathrm{CP}$, es el hecho de que la acusada se aprovechaba de su posición privilegia$\mathrm{da}^{20}$. El referido precepto se formula para «autoridad o funcionario público» (siendo pertinente su aplicación), pero la posibilidad efectiva de perpetrar el delito no venía dada por tal status, sino por razón de su profesión, de la cual forma parte nuclear el deber de secreto. En otras palabras: un administrativo, celador o recepcionista también vería agravada su pena por el mismo motivo: ser funcionario público. Pero el hecho de tener acceso a los datos viene dado por su condición de enfermera, que lleva aparejada, a esa facultad de acceso, el

20 Esta apreciación, sin embargo, sí aparece recogida en el Auto del Tribunal Supremo 130/2018, de 21 de diciembre de 2017, Fundamento de Derecho Primero, letra c: «La acusada, aprovechando su profesión de enfermera, siendo contratada como personal laboral por el Servicio Navarro de Salud y consciente del compromiso de confidencialidad que había contraído, accedió al historial médico de Matías sin su consentimiento y sin que mediara relación asistencial entre ellos, utilizando sus claves como trabajadora». 
deber de secreto ${ }^{21}$. Este mandato con rango legal viene dado por la meridiana redacción del art. 7 de la Ley de Autonomía del Paciente ${ }^{22}$ :

\section{«Artículo 7. El derecho a la intimidad.}

1. Toda persona tiene derecho a que se respete el carácter confidencial de los datos referentes a su salud, y a que nadie pueda acceder a ellos sin previa autorización amparada por la Ley.

2. Los centros sanitarios adoptarán las medidas oportunas para garantizar los derechos a que se refiere el apartado anterior, y elaborarán, cuando proceda, las normas y los procedimientos protocolizados que garanticen el acceso legal a los datos de los pacientes.»

No en vano, el art. 199.2 del Código Penal prevé una modalidad agravada para: «El profesional que, con incumplimiento de su obligación de sigilo o reserva, divulgue los secretos de otra persona». Este es el caso específico de medicina y enfermería, pero también de otros agentes como abogados ${ }^{23}$ o sacerdotes que, por razón de su profesión, obtienen acceso a la parcela más íntima de las personas, quienes les confían sus problemáticas bajo la premisa de que no serán reveladas. Ello explica que, para este tipo agravado, se acompañe la pena privativa de libertad (uno a cuatro años) con una de inhabilitación especial para la profesión habitual de dos a seis años. En el caso objeto de estudio, la agravante aplicada fue la del art. 198 CP (funcionario público que comete el acto típico prevaliéndose de su cargo, lo que justifica que se imponga inhabilitación para

21 De hecho, la cautela tiene una doble vertiente. En primer lugar, se predica respecto de todas las informaciones que obtenga el profesional sanitario en el ejercicio de sus funciones. $Y$ en segundo, es el deber de abstenerse de inmiscuirse en los historiales de pacientes con los que no tiene relación profesional, como veremos a renglón seguido. Asimismo, el art. 2.7 de la Ley de Autonomía del Paciente 41/2002 establece que: «La persona que elabore o tenga acceso a la información y la documentación clínica está obligada a guardar la reserva debida.»

22 Ley 41/2002, de 14 de noviembre, básica reguladora de la autonomía del paciente y de derechos y obligaciones en materia de información y documentación clínica. Publicada en el BOE, n. ${ }^{\circ} 274$, de 15 de noviembre de 2002, páginas 40126 a 40132.

23 Blasco Soto, M. DEL C.: «La protección de datos personales y el secreto profesional de abogados y procuradores», en Pedraz Penalva, E., Protección de Datos y Proceso Penal, La Ley Wolters Kluwer, Las Rozas, 2010, p. 104 (libro electrónico formato EPUB): «(...) si tienen ficheros de clientes, están obligados al deber de secreto sobre esos ficheros conforme lo establecido en el art. 10 de la LOPD. Entiendo, a diferencia de algún sector doctrinal que el deber de secreto recogido en esta norma y el deber de secreto profesional no pueden ser tratados como si fueran instituciones similares, y esto es así porque la exigencia y los límites de su protección no son los mismos». Aunque en el contexto de abogados y procuradores, mutatis mutandi puede incorporarse sin grandes dificultades el fino apunte relativo al deber de secreto y su doble vertiente penalística y de protección de datos. 
el mismo), en relación al art. 197.2 y 197.6 CP. El hecho típico que se prevé es el acceso «sin estar autorizado» a «datos reservados de carácter personal», que encaja perfectamente en la conducta de la acusada.

Tras afianzar estos precedentes, los hechos probados de la sentencia recogen otra serie de extremos de obligada mención. Así, se refleja que el régimen de visitas de los nietos de la acusada con su padre quedó regulado en virtud de sentencia de 18 de noviembre de 2010. En ningún momento la resolución parece prestar atención al hecho de que apenas transcurrieron 2 meses desde la sentencia en sede civil hasta que la acusada comenzó a espiar a su ex yerno (enero 2011). Resulta llamativo este dato, pues podría apuntar no solamente a la obcecación en la defensa de sus nietos (como justificó la acusada), sino a una suspicacia desmedida o incluso inquina personal, móviles cuya apreciación no aparece valorada (si bien sí que se aprecian veladas referencias en las manifestaciones de víctimas y acusada recogidas en la resolución, a las que nos referiremos posteriormente).

Con todo, lo más llamativo, es que no se ponderase que, de existir un peligro real para los menores al estar con su padre, tales hechos habrían sido valorados y dirimidos en sede civil a la hora de establecer el régimen de visitas con su padre, máxime a la vista de la proximidad entre dicha resolución (18 de noviembre 2010) y el inicio del seguimiento (31 de enero 2011). Tampoco aparece acreditado que el juzgador civil suspendiese en algún momento el régimen de visitas por un peligro real para los menores durante los años que duró la intromisión. Sin duda, el juez de primera instancia habría reaccionado (como auténtico valedor y protector del interés superior del menor), incluso vía art. $158 \mathrm{CC}$, de haber conocido cualquier hecho que pusiese en peligro a estos. No consta que los hechos que llevaron a la acusada a espiar sistemáticamente a las víctimas fuesen puestos en conocimiento de la autoridad judicial para que tomase las medidas oportunas, ni que, de haberlo hecho, hubiesen sido de suficiente entidad como para acordar una suspensión del régimen de visitas de los menores con su padre.

No obstante lo anterior, debe remarcarse que sí se encuentra acreditado en los hechos probados que el padre de los menores fue tratado de sus adicciones en el año 2011 (estuvo de baja desde el 22 de julio de 2011 hasta el 9 de septiembre), sufriendo una recaída desde finales de noviembre de 2012 hasta abril de 2013. Encontramos lagunas en la resolución, que considera un hecho probado que «tales circunstancias generaron en la acusada una intensa preocupación por el bienestar de sus nietos cuando se encontraban en compañia de su padre, temiendo por la seguridad de éstos, llegando a convertirse en una verdadera obsesión, que le 
producía un importante estado de ansiedad. Como consecuencia de ello, y con el ánimo de tratar de proteger a dichos menores, se introdujo en repetidas ocasiones en la bistoria clínica del Sr. Cirilo y de su nueva pareja, Adelaida [sic], de la que igualmente sospechaba que pudiera tener problemas de adicciones parecidos». Pero, sin embargo, confrontando las fechas advertimos que el espionaje se inició medio año antes de la primera crisis, en enero de 2011, y continuó mucho más allá de la segunda, hasta 2015. En cuanto a la nueva pareja, parece de todo punto inaceptable el argumento de que «igualmente sospechase que pudiera tener problemas de adicciones parecidos», sin que exista prueba alguna de los mismos, resultando en una violación de su intimidad absolutamente censurable.

A efectos de aplicación de la atenuante de reparación del daño, la acusada «procedió en fecha 22 de julio de 2016 a consignar (...) la cantidad de 1.200 euros, correspondiente al importe de la responsabilidad civil solicitada por el Ministerio Fiscal para los perjudicados (600 euros para cada uno)», siendo formalmente suficiente para obtener la atenuante, pues coincide con las cantidades solicitadas por el Ministerio Fiscal como daño moral. A este respecto, podría argüirse que cada invasión (108 en la historia clínica de su exyerno, 107 en la de su nueva pareja) en una esfera tan íntima de la persona como es el historial médico, tiene un valor tan pobre que no alcanzaría siquiera a los 6 euros por cada una de ellas. De aceptar este cálculo, estaríamos asumiendo que cada violación de la privacidad supone un coste unitario inferior al valor mínimo de una hora de trabajo bajo el parámetro del salario mínimo interprofesional. En este sentido, resulta criticable la petición formulada por el Ministerio Fiscal, que infravalora la importancia de la violación de dos derechos fundamentales de las víctimas: la intimidad (información muy sensible) y la autodeterminación informativa (auténtico seguimiento y control de su estado de salud durante años).

Finalmente, resulta relevante puntualizar que no existe prueba de que la información obtenida por la acusada fuese comunicada a terceros. Este elemento fáctico, determinante en sede penal a efectos de valorar la gravedad del delito, y cuya ponderación es perfectamente ajustada a derecho en la resolución de referencia, no es incompatible con la ironía de que la acusada pueda beneficiarse de un presunto comportamiento «discreto» o «reservado» respecto de la información obtenida violando la intimidad de las víctimas.

Esta «circunspección» en el trato de la intimidad de las víctimas se habría mantenido sostenida en el tiempo durante cuatro años. Un tratamiento ajustado a derecho de la presunción de inocencia exige que quede descartada la 
revelación del secreto ${ }^{24}$ a terceras personas, pues no existe ninguna prueba que lo acredite, lo que desecha completamente la comisión del tipo contenido en el art. 199.2 $\mathrm{CP}^{25}$, cuestión obvia sobre la que no merece la pena extenderse. Pero ello no es óbice para apreciar el interesante cruce de papeles, en el que la acusada pasa de inmiscuirse ilícita y reiteradamente en la intimidad de las víctimas, a ser guardiana inquebrantable de sus secretos.

\section{RAZONAMIENTOS DE LA SALA. REVISIÓN Y VALORACIÓN}

A continuación, vamos a sintetizar los argumentos jurídicos que el Tribunal Supremo ha recogido en sus fundamentos de derecho para alcanzar el fallo controvertido: rebajar la pena impuesta por la APC de 1 año y 10 meses de prisión y 5 años de inhabilitación, a 1 año por cada delito y cuatro años de inhabilitación.

El primer fundamento de derecho no contiene información relevante para la cuestión objeto de análisis en este trabajo, si bien, para completar el relato de hechos apenas ofrecido, cabría recuperar algunas manifestaciones de las víctimas recogidas en dicho fundamento primero. Así, la nueva pareja del ex yerno manifestó en su recurso que nunca había sido consumidora de drogas, señalando de igual modo las «iras, insidias e injurias de la acusada» que refirió haber recibido incluso desde antes del nuevo enlace matrimonial. Afirma el tribunal a este respecto que: «la inferencia de falta de simpatía no parece improbable, pero en nada afecta a la comisión delictiva imputada, ni a las atenuantes estimadas, sino más bien, abona la concurrencia de obcecación». Evidentemente los posibles ilícitos penales que pudieran derivarse de dichas acciones no tenían cabida en el objeto de este procedimiento, por lo que huelga cualquier consideración adicional al respecto. Sin dejar de ser cierto, con esto se están con-

24 BarReiro Jorge, A., «El delito de descubrimiento y revelación de secretos en el código penal de 1995: un análisis del artículo 197 del CP», en Revista jurídica Universidad Autónoma de Madrid, n. ${ }^{\circ}$ 6, pp. 99-131, <https://repositorio.uam.es/handle/10486/3091>, 2002 (15 de abril de 2018).

25 Bolea Bardón, C.: «Comentario al artículo 199», en Corcoy Bidasolo, M. y Mir Puig, S. (dirs.), Comentarios al Código Penal (Reforma LO 1/2015 y LO 2/2015), Tirant lo Blanch, Valencia, 2015, pp 738-739. En efecto, como indica esta autora, la aplicación de este tipo presupone: «que se ha conocido el secreto de forma lícita, castigándose sólo su revelación», extremo que en el caso de estudio no puede considerarse probado. Adicionalmente a lo anterior, exigiría que: «al carácter profesional del sujeto activo bay que añadir que la propia relación entre el profesional y el sujeto titular debe obligar a éste a confiar al profesional sus secretos personales para poder ejercer su actividad». 
validando todos los abusos cometidos por la acusada, amparándolos dentro de una atenuante («abona la concurrencia de obcecación»), y sin miramiento al sufrimiento de la víctima.

El fundamento segundo recoge que la acusada «'presentaba proceso adaptativo con ánimo bajo y ansiedad, secundario a problemas familiares, que requirió tratamiento con ansioliticos y antidepresivos e incapacidad laboral del 1 de octubre de 2010 al 20 de enero de 2011', añadiendo que desde entonces, el trastorno se ba agudizado en varias ocasiones, continuando en la actualidad con tratamiento farmacológico». La defensa de las víctimas puso en duda que fuese suficiente para justificar el estado de obcecación desde 2011 hasta 2015. El Tribunal Supremo no acepta este planteamiento, pero desde un punto de vista clínico, podría afirmarse que estas dolencias en la psiquis de la acusada, no encajan de forma natural en el estado de obcecación alegado (y solo parcialmente probado) durante cuatro años, como sí lo harían, por ejemplo, un trastorno obsesivo-compulsivo. En todo caso, resulta difícil sostener, de un lado, que la acusada se encuentra en tratamiento farmacológico desde 2010, y del otro, que ningún tratamiento en cuatro años esté surtiendo efecto. La propia Sala reconoce que: «Ciertamente, es difícil de comprender e interpretar la conducta realizada por la acusada a lo largo de los años en que de forma continuada vino accediendo a los historiales clinicos de los querellantes, baciéndolo ya de una forma que no cabría sino calificar de obsesiva y propia de una fijación cuasi enfermiza», refiriendo, a continuación, que incluso en el ejercicio del derecho a última palabra, volvió a reiterar su discurso. De ello, tanto el Ministerio Fiscal como el Alto Tribunal deducen que la atenuante de obcecación reviste «cierta intensidad», cuestión que va a ser determinante para la rebaja de la pena.

Lo más importante del fundamento tercero es el análisis que hace el Tribunal Supremo sobre la aplicación de la atenuante de obcecación del art. 21.3 CP al caso de estudio. Cita en su apoyo la STS 161/2017, según la cual: «la disminución de la imputabilidad que se produce por ofuscación de la mente y de las vivencias personales determinados por una alteración emocional fugaz (arrebato) o por la más persistente de incitación personal (obcecación) pero siempre produciéndose por una causa o estímulo poderoso»; a lo que cabría añadir que se trate de una fuerza de tal magnitud que doblegue la voluntad y el raciocinio de la persona. Sería un medio probatorio adecuado para ello que existiese una base médicopatológica, si bien esta exigencia no es indispensable para su estimación a ojos del Tribunal Supremo, siendo esta cuestión pacífica en la jurisprudencia.

La resolución también acoge, en este punto, la importancia del estímulo que llevó a la acusada a cometer el ilícito: el bienestar de sus nietos. A este 
respecto, afirma, que «no solo no contradice norma socio-cultural alguna, sino que conlleva una ponderación positiva, social y normativa» ${ }^{26}$, valoración que criticaremos en el apartado siguiente de este trabajo. En conexión con el estímulo mencionado, aparecería la «perturbación» que sintió la acusada, procedente de la «intensa preocupación por el bienestar de sus nietos cuando se encontraban en compañía de su padre, temiendo por la seguridad de estos». Por último, y siendo lo menos relevante, vale la pena recuperar a efectos ilustrativos de la relación entre víctimas y acusada, la manifestación efectuada por esta última en el plenario, referente a la nueva pareja de su ex yerno de quien: «igualmente sospechaba que pudiera tener problemas de adicciones parecidos».

El fundamento cuarto versa sobre la atenuante de reparación del daño prevista en el art. 21.1 CP. Poco puede añadirse en este aspecto, pues lo cierto es que la acusada ingresó íntegramente las cantidades solicitadas por el Ministerio Fiscal (600 euros por cada víctima). No se manifestó arrepentimiento por parte de la condenada, pero no se precisa para la aplicación de la referida atenuante (SSTS 791/2017, de 7 de diciembre; 239/2010 de 24 de marzo; $1028 / 2010$, de 4 de noviembre). El fundamento quinto apenas goza de contenido, pues se limita a certificar que las atenuantes recién expuestas se encuentran debidamente ponderadas en la condena impuesta.

26 En este aspecto, ahonda el Tribunal: «En ambas modalidades precisa para su estimación que haya en su origen un determinante poderoso de carácter exógeno o exterior y de entidad suficiente para desencadenar un estado anímico de perturbación y oscurecimiento de sus facultades psíquicas con disminución de las cognoscitivas o volitivas del agente, de modo que sin alcanzar la cualidad propia del trastorno mental transitorio completo o incompleto, exceda del leve aturdimiento que suele acompañar a ciertas infracciones. Como regla general 'el estímulo ha de ser tan importante que permita explicar (que no justificar) la reacción concreta que se produjo. Si esta reacción es algo absolutamente discordante, por exceso notorio, respecto del hecho motivador, no cabe aplicar la atenuación' (STS 256/2002, de 13 de febrero). Además, tales estímulos no han de ser reprochados por las normas socio-culturales que rigen la convivencia social y deben proceder del precedente comportamiento de la víctima, con una relación de causalidad entre los estímulos y el arrebato u obcecación y una conexión temporal, sino inmediatos si próximos, entre la presencia de los estímulos y el surgimiento de la emoción o pasión (SSTS 1110/96 de 20 de diciembre, 1479/99 de 18 de octubre). Es preciso también que en el entorno social correspondiente no sean tales estímulos repudiados por la norma socio-cultural imperante, lo que significa que la actuación del agente se ha de producir dentro de un cierto sentido ético ya que su conducta y sus estímulos, no pueden ser amparados por el Derecho cuando se apoyan en una actitud antisocial reprobada por la conciencia social imperante, que en esta relación de causa o afecto entre el estímulo desencadenante y la conducta ha de darse una conexión temporal y que cualquier reacción colérica que las que, con frecuencia, acompañan a ciertas acciones delictivas, no basta para la estimación de la atenuante.» 
El fundamento sexto es sencillo, pero sustentará una importante crítica en el apartado siguiente. El contenido sobre el que versa es la cuantificación del daño moral. El Tribunal Supremo sostiene el siguiente argumento: «los secretos fueran descubiertos al entrar ilícitamente en la historia clínica de las víctimas, no incrementa por 107 veces el daño moral sufrido».

El fundamento séptimo es el más relevante de la resolución. Aquí deben distinguirse dos cuestiones bien diferencias. De un lado, los principios de derecho penal que amparan la aplicación de la atenuante de obcecación en dos grados en lugar de uno (cuestión incardinada en la capacidad valorativa del tribunal ex. arts. 120.3 CE y $72 \mathrm{CP}$ ); y del otro, la argumentación utilizada, construida en parte sobre la noción de que la acusada se movía por un interés «que atiende a un bien normativo constitucionalizado como es el interés del menor», a lo que añade que el peligro era percibido como «inminente y constante para sus nietos, temiendo por la seguridad de estos ante comportamientos desajustados que pudieran protagonizar aquellos».

\section{ANÁLISIS Y COMENTARIO DE LA SENTENCIA}

IV.1. Sentencias de contraste y últimas tendencias en la jurisprudencia del Tribunal Supremo en acceso ilegítimo a datos médicos

Históricamente, la vulneración de la intimidad del paciente a través de la violación del secreto médico ha venido valorándose de forma rigurosa por el Tribunal Supremo, habida cuenta no solo de la naturaleza especialmente sensible de los datos obtenidos y cómo afecta a la intimidad de los afectados, sino también del conocimiento especializado que tienen los profesionales sanitarios sobre la importancia del mismo y la exigencia legal de deber de secreto que preside todas sus actuaciones. El alcance constitucional de las vulneraciones en esta materia fue objeto de análisis por el Tribunal Constitucional en su STC 70/2009, de 23 de marzo, en la que se concedió el amparo a un funcionario cuyos informes médicos habían sido aportados por la administración a un procedimiento para declarar su jubilación sin su consentimiento ${ }^{27}$.

27 En la misma línea, vid. STC 159/2009, de 29 de junio. Publicada en el BOE, n. ${ }^{\circ} 181$, de 28 de julio de 2009, pp. 94 a 106. 
En su fundamento segundo, establece las bases constitucionales sobre las que se asienta la historia clínica:

«(...) constituye doctrina consolidada de este Tribunal que el derecho a la intimidad personal garantizado por el art. $18.1 \mathrm{CE}$, estrechamente vinculado con el respeto a la dignidad de la persona (art. 10.1 CE), implica la existencia de un ámbito propio y reservado frente a la acción y el conocimiento de los demás, necesario, según las pautas de nuestra cultura, para mantener una calidad mínima de la vida bumana.» Asimismo, recuerda que: «La afectación a la intimidad del recurrente sólo es constitucionalmente legítima si resulta proporcionada, y sólo resulta proporcionada si, entre otros requisitos, no existen otras medidas menos gravosas que, sin imponer sacrificio alguno del derecho fundamental a la intimidad, o con un menor grado de sacrificio, puedan ser igualmente aptas para conseguir dicho fin».

Resulta fácil encontrar el paralelismo con el presente caso, que llama la atención en cuanto a la total quiebra de la necesaria proporcionalidad entre el comportamiento de la acusada y la finalidad que manifestaba perseguir ( «la protección de los menores»).

La anterior resolución resulta clarificadora y permite sentar las bases de la intimidad y la protección de datos en relación con la salud desde un plano constitucional y de derechos fundamentales. Uno de ellos es la dignidad de la persona, como también señala PINEDO GARCÍA: «Por ello, los derechos a la protección de la intimidad personal y protección de datos de carácter personal persiguen garantizar a sus titulares un poder de control sobre su uso y destino, con el propósito de impedir su tráfico ilícito y lesivo para la dignidad (...) $\gg^{28}$. A la vista de los hechos expuestos, podría afirmarse que las víctimas del caso objeto de estudio también han visto lesionado su derecho fundamental a la dignidad personal del art. $10.1 \mathrm{CE}$.

Entrando ahora en la esfera penal, resulta útil por su valor didáctico la sentencia del Tribunal Supremo 532/2015, de 23 de septiembre. En efecto, en esta resolución parece dotarse de gran importancia a la protección de la

28 Pinedo García, I., «Protección de datos sanitarios: la historia clínica y sus accesos», en CESCO: Revista de Derecho de Consumo, n. ${ }^{\circ} 3$, p. 308, <https://www.revista.uclm.es/index.php/cesco/ article/view/421/363>, 2013 (13 de abril de 2018). 
información contenida en la historia clínica ${ }^{29}$. Así, en su fundamento jurídico quinto, se reivindica que:

«toda persona tiene derecho a que se respete el carácter confidencial de los datos referentes a su salud y a que nadie pueda acceder a ellos sin previa autorización amparada por la Ley, formando parte de su derecho a la intimidad (art. 7.1 Ley 41/2002 de 14 de noviembre, básica reguladora de la autonomía del paciente y de derechos y obligaciones en materia de información y documentación clínica). La bistoria clínica definida en el art. 3 de esta ley como el conjunto de documentos que contienen los datos, valoraciones e informaciones de cualquier índole sobre la situación y la evolución clínica de un paciente a lo largo del proceso asistencial, estaría comprendida en ese derecho a la intimidad y además forma parte de los datos sensibles, el núcleo duro de la privacidad, cuyo mero acceso, como hemos descrito, determina el perjuicio de tercero; el del titular de la historia, cuyos datos más intimos, sobre los que el ordenamiento le otorga un mayor derecho a controlar y mantener reservados, se desvelan ante quien no tiene autorizado el acceso a los mismos».

Este alto estándar de protección no aparece reflejado en modo alguno en la resolución de referencia. Se echa en falta una exposición tan clara como esta, que hubiera permitido confrontar los bienes jurídicos en liza y ponderar su peso, sirviendo como argumentaciones que redundarían en una mejor fundamentación y comprensión de la sentencia.

También contrasta la reducción de la pena en el caso de análisis con, por ejemplo, la rigidez sostenida por el propio Tribunal Supremo en su sentencia 40/2016, de 3 de febrero. En ella, se condena a un médico por acceder al historial médico de su ex esposa. Explica la Sala:

«Se trata de un delito que supone el conocimiento y voluntad en la acción realizada actuando a sabiendas, en tanto que el perjuicio se refiere al peligro de que los datos albergados en las bases de datos protegidas puedan llegar a ser conocidos por personas no autorizadas. En el caso ese perjuicio se ha producido, y el autor lo pretendió al tomar conocimiento de un dato personal especialmente sensible en nuestro ámbito cultural, inherente a la intimidad más estricta que no interesa sea conocido fuera de la privacidad y hacerlo con conocimiento de una actuación contraria a la norma que permite su acceso. El perjuicio se realiza cuando se apodera, utiliza, modifica o accede a un dato protegido con la intención de que su contenido salga del ámbito

29 Berrocal Lanzarot, A. I., «La protección de datos relativos a la salud y la historia clínica», en Revista de la Escuela de Medicina Legal, n. ${ }^{\circ}$ 18, pp. 34, 38 y 39, <http://webs.ucm.es/centros/cont/ descargas/documento30950.pdf>, 2011 (13 de abril de 2018). 
de privacidad en el que se incluyó en una base de datos, archivo, etc, especialmente protegido, porque no es custodiado por su titular sino por titulares de las bases con especiales exigencias de conductas de protección. Así lo expusimos en la STS de 11 de julio de 2001, al reseñar que el perjuicio exigido va referida a la invasión de la intimidad y no a la producción de un quebranto económico patrimonial concreto. En la STS 532/2015, de 23 de septiembre, se refiere ese perjuicio en un supuesto similar al presente porque perjudica a su titular al tratarse de datos sensibles por su naturaleza cuyo acceso ya perjudica a su titular.»

Además, en tal caso, se produjeron un total de 171 accesos que, según la Sala, fueron: «de forma inconsentida e ilegítima, realizados con aprovechamiento de identidad de circunstancias que permite la aplicación de la continuidad delictiva. Cada uno de los accesos tiene entidad propia y diferenciada de los otros (...)». Llama la atención el cariz de esta resolución en contraste con la sentencia objeto de estudio, donde, de hecho, se produjeron más accesos ilegítimos (215 frente a 171), pero con un discurso mucho menos duro.

Esta línea garantista con la intimidad de los datos relativos a la salud de los pacientes se encuentra también en la STS 778/2013, de 22 de octubre. El contraste con la sentencia objeto de estudio es extremo, ya que en este caso, se trataba de un médico que divulgó información relativa a implantes mamarios en mal estado que suponían un peligro acreditado para la salud de las mujeres portadoras de determinados implantes mamarios. El Alto Tribunal valora que existe un error en la justificación del médico («el acusado al que se reprocha la conducta actuó en defensa de la salud de las indemnizadas, creyendo estar amparado en su actuación, lo que permite proporcionar la consecuencia jurídica al becho») ${ }^{30}$. Pero en cuanto a la cuestión que nos ocupa en el presente estudio, debemos rescatar el fundamento jurídico primero, que taxativamente declara: «En la situación fáctica descrita la conducta del acusado es típica del descubrimiento de secretos pues nada puede justificar la agresión a la intimidad de los pacientes, documentada en unos historiales clínicos que gozan de especial protección jurídica (Ley General de

30 Nótese la dicotomía al que se exponía el cirujano. El Tribunal Supremo declara: «No se trata de un error de probibición sino de una justificación de su conducta por el cumplimiento de un deber, art. 20.7 del Código penal. La conducta de poner en conocimiento de la autoridad competente para la depuración de lo que entiende son hechos delictivos no es revelar secretos, sino cumplir con la obligación impuesta en el art. 259 y ss de la Ley de enjuiciamiento criminal, el deber de denunciar impuesto legalmente y con especial intensidad al médico (art. 262 de la Ley de enjuiciamiento criminal).» Destaca este caso porque, en comparación con el de referencia, el profesional sanitario sí obraba en cumplimiento de sus obligaciones y tenía un mandato legal que le respaldaba. 
Sanidad, ley 14/1986; Real Decreto 63/1995 - derecho a la confidencialidad-; Ley Orgánica de Protección de Datos LO 15/1999; y Ley reguladora de la autonomía del paciente, Ley 41/2002, de 14 de noviembre).» La diferencia es muy clara. En este caso, el acusado sí se hace acreedor de una rebaja en su pena, porque llevó a cabo actuaciones moralmente correctas para salvaguardar el bien jurídico que decía proteger con sus actuaciones (la salud de las pacientes con implantes defectuosos). En concreto, se procuró asesoramiento legal y puso los hechos en conocimiento del Ministerio Fiscal. Por su parte, en la resolución de referencia, la acusada no llevó a cabo ningún acto que diese virtualidad o efecto a la protección de los menores, y desde luego, tampoco se aprecia en el Tribunal el mismo listón garantista en la intimidad de los pacientes.

Para terminar, recuperamos un caso que será resuelto previsiblemente a lo largo de 2018 por el Tribunal Supremo, y que servirá también de importante contraste con la resolución objeto de estudio. Se trata de la sentencia 225/2017 de la Sección 3. a de la Audiencia Provincial de Cantabria de fecha 9 de junio de 2017, rollo 3/2017. Su relevancia radica en que el supuesto de hecho resulta, a todas luces, mucho menos lesivo que el de la sentencia de referencia, y sin embargo lleva aparejadas mayores responsabilidades civiles y penales.

En este caso, la APC declara probado que el acusado, médico de atención primaria, accedió ilegítimamente a través de la aplicación informática del Servicio Cántabro de Salud al historial médico de la víctima los días 31 de enero (desde las 16:50:07 horas hasta las 16:50:22, a resultados de análisis de laboratorio de bioquímica) y 8 de febrero de 2013 (de 16:38 a 16:40 horas, a informes de atención primaria, consultando en concreto varios diagnósticos y episodios clínicos de la víctima).

El motivo que llevó al acusado a perpetrar estos dos accesos ilegítimos es importantísimo, ya que introduce un elemento atinente a derechos fundamentales. Si en la sentencia de estudio la acusada alegó actuar «en defensa del interés del menor», y el Alto Tribunal consideraba que tales hechos «atienden a un bien normativo constitucionalizado como es el interés del menor, y además actúa ante la creencia de un peligro inminente y constante, creencia pues de una causa de justificación», en la sentencia de contraste encontramos que también el acusado atendió a un bien normativo constitucionalizado, como es el derecho a la integridad física (art. 15 CE). Así, la Audiencia Provincial de Cantabria recoge que: «lo bizo a resultas de unos problemas de salud, en concreto de una enfermedad de transmisión sexual que tanto él como su esposa contrajeron a consecuencia de la relación extramatrimonial que su esposa, según sus propias afirmaciones, mantuvo durante el año 2008 (...)» con la víctima. 
La APC no admite tal justificación, pues: «el dolo de dicha conducta no queda desvirtuado por la naturaleza del fin u objetivo perseguido por el recurrente en última instancia», afirmación para la que se apoya en las SSTS de 6 de octubre de 2015, 18 de octubre de 2012, de 8 de octubre de 2010 y de 6 de febrero de 2009. A lo anterior, añade: «carece de relevancia a dicho fin, si el imputado realiza la acción con intención de hacer un favor, de complacencia, por afinidad personal o para cualquier causa, lo relevante es si cuando realiza la acción comprendía el alcance de la norma probibitiva y si era capaz de actuar conforme a esa comprensión. En consecuencia, la consideración de los motivos es irrelevante a efectos penales, salvo cuando se recoge como elemento del tipo penal o se tiene en cuenta en circunstancias modificativas de la responsabilidad penal».

Entre las diferencias más destacadas entre ambas sentencias, cabe citar, en primer lugar, la cuantía de la indemnización, mucho más alta (2000 euros frente a 750 euros) por muchos menos accesos y sin seguimiento extendido en el tiempo (solo 2 accesos frente a 107 y 108). Y también porque el motivo del acusado en este caso era mucho más razonable y su actuación, aunque penalmente censurable, mucho más comedida, proporcionada, y ajustada a las justificaciones esgrimidas $^{31}$. La pena es muy desproporcionada comparativamente, ya que es mucho más alta, al igual que la indemnización. Es más gravosa a pesar de haber accedido un número mínimo de veces, y por miedo del acusado a haberse contagiado inadvertidamente de alguna enfermedad de transmisión sexual, fruto de una relación extramatrimonial de su mujer. También resulta notable la exposición que hace la Audiencia Provincial sobre las condiciones subjetivas de este tipo de profesionales, a la hora de justificar la comisión del tipo delictivo, es decir, el acceso a datos de salud de terceras personas sin autorización ni consentimiento:

«lo cierto es que en el presente caso no puede aceptarse que el acusado actuara en la errónea creencia, ni tan siquiera vencible, de actuar con arreglo a derecho, babida cuenta su formación académica así como su larga trayectoria como médico del Servicio Cántabro de Salud.

31 No obstante, debemos estar con la Audiencia Provincial de Cantabria cuando constata: «la sala no puede dar credibilidad alguna a la afirmación del acusado de que cuando accedió a la bistoria clínica [de la víctima], en los años 2012 y 2013, lo hizo para comprobar si dicho individuo padecía alguna enfermedad de transmisión sexual que les pudiera baber contagiado, máxime cuando en dichas fechas ya habian transcurrido entre cuatro y cinco años desde el cese de la relación extramatrimonial, no siendo por ello probable que subsistiera un riesgo cierto de nuevos contagios, pudiendo el acusado y su esposa para conjurar dicho temor haberse sometido a cuantas pruebas de detección de enfermedades bubieran tenido por conveniente, en lugar de realizar la conducta aquí enjuiciada que se muestra totalmente innecesaria a dicho fin.» 
Así pues, no puede desconocerse que cualquier funcionario público con un conocimiento minimo de los valores constitucionales y de los derechos individuales reconocidos en la Constitución, con mayor razón si ostenta las responsabilidades que correspondian al acusado, necesariamente tiene que conocer que los datos relativos a la bistoria clínica de los pacientes son confidenciales, no pudiendo accederse a los mismos nada más que con motivo de una relación asistencial. Así pues, es un becho que necesariamente tenía que ser conocido por el acusado, por estar incluso recogido en el código deontológico de la profesión médica, y regulado en la Ley 41/2002, de 14 de noviembre, básica reguladora de la autonomía del paciente (...)».

Queda por determinar si el Tribunal Supremo, cuando resuelva el recurso presentado frente a la sentencia de la Audiencia Provincial de Cantabria, atenderá cualitativamente a los motivos del mismo modo que en la resolución de estudio; o si, por el contrario, se abordará como una cuestión meramente cuantitativa, manifestada como la obstinada reiteración en la conducta delictiva y su pertinaz justificación ad-hoc.

\section{IV.2. Crítica a los puntos controvertidos de la resolución}

Del análisis de la sentencia, encontramos que pueden extraerse, al menos, tres aspectos accesorios (considerando la ponderación de la intimidad vs. interés superior del menor como la cuestión principal) susceptibles de recibir una crítica fundada y constructiva respecto de los argumentos y justificaciones sobre los que se sostienen.

a) Apreciación y valor probatorio del estado psicológico de la acusada

En primer lugar, en su fundamento de derecho segundo, la sentencia incorpora al debate jurídico el hecho de que la acusada aportó informe médico según el cual: «'presentaba proceso adaptativo con ánimo bajo y ansiedad, secundario a problemas familiares, que requirió tratamiento con ansioliticos y antidepresivos e incapacidad laboral del 1 de octubre de 2010 al 20 de enero de 2011', añadiendo que desde entonces, el trastorno se ha agudizado en varias ocasiones, continuando en la actualidad con tratamiento farmacológico».

Por tanto, el tratamiento que consta probado (no hay mención alguna a material probatorio que acredite las recaídas o continuidad del mismo) comenzó el 1 de octubre de 2010 (antes de la sentencia de medidas paterno-filiales, de 10 
de noviembre) y terminó el 20 de enero (antes de la primera intromisión, el 31 de enero). Esto demuestra que para cuando se produjo el primer acceso ilegítimo ya se encontraba en tratamiento, con el cual llevaba 4 meses.

Sin embargo, dicho tratamiento se refería a la enfermedad de ansiedad, y no a la de trastorno obsesivo-compulsivo o personalidad obsesiva, tal vez más cercanos a comportamientos asimilables al concepto de obcecación, y más compatible con la reiteración de los accesos ilegítimos durante años. Por tanto, la idoneidad de esta información sobre la patología y su valor probatorio a efectos de circunstancia atenuante de la responsabilidad penal no es el más óptimo. Sentado lo anterior, en este punto debemos recordar que las entidades clínicas o bases patológicas no son necesarias para la estimación de la referida atenuante de obcecación (STS 2197/02, de 26 de diciembre; sin embargo, en la STS 59/02 de 25 de enero, ostentando rasgos de personalidad obsesiva, no se estimó tal atenuante), cuestión que introduce un importante sesgo interpretativo, en detrimento de fundamentos científicos.

Pero a mayor abundamiento, resulta bastante incomprensible que, con los síntomas tan aparentemente llamativos que presentaba la acusada, en ningún momento se le pautase un tratamiento que aplacase su estado alterado. Es más, resulta improbable que, en cuatro años de tratamiento, no haya existido ningún fármaco efectivo que haya servido para reequilibrar la psique de la acusada, habida cuenta que persistió en el espionaje y seguimiento de las víctimas durante tan prolongado tiempo.

De ello, cabe deducir, o bien que la acusada sufre un trastorno incurable (extremo que no consta probado), o bien, si el tratamiento funcionó, que el estado psicológico no tuvo influencia en su comportamiento. En este escenario, la actitud dolosa u obcecada se encontrarían separadas por una muy delgada línea. Dado que la Audiencia Provincial de Cáceres pudo apreciar en persona el estado alterado de la acusada, y en respeto al principio de inmediación, debemos aceptar la existencia de la atenuante apreciada, pero a la vez ponemos en duda si su magnitud alcanza para conceder una rebaja en dos grados.

b) Insuficiencia en la valoración y alcance del derecho fundamental a la intimidad

Por los fundamentos ya expuestos en el apartado I de este trabajo, se encuentra fuera de toda duda la consideración de la intimidad como uno de los bienes jurídicos y derechos fundamentales más importantes de nuestro De- 
recho, merecedores de un elevado estándar protección, dada su configuración normativa al más alto nivel. Sin embargo, no cabe explicación lógica que permita comprender por qué la cuantificación o modulación de la indemnización impuesta a las víctimas es tan insignificante.

Carece de todo razonamiento o explicación la sentencia en este punto ${ }^{32}$, más allá del desafortunado inciso del fundamento jurídico sexto, apartado $2 .^{\circ}$ : «los secretos fueron descubiertos al entrar ilícitamente en la bistoria clínica de la víctima, pero no se incrementa por 107 veces el daño moral sufrido». El razonamiento es tan peregrino que llama poderosamente la atención que esa sea toda la argumentación que realiza el más alto estamento judicial del país para la valoración de una violación del derecho fundamental a la intimidad, constitucionalmente recogido en el art. 18.1 y 18.4 .

Es bien sabido que la valoración del daño moral es «de compleja determinación», como de pasada menciona la Sala en el Fundamento de Derecho Séptimo, apartado $3 .^{\circ}$ CASADO ANDRÉS ha recopilado las últimas tendencias doctrinales y jurisprudenciales en esta materia, concluyendo que: «El concepto del daño moral se fundamenta en los sentimientos, en el sufrimiento, en la reputación o en la angustia, en fin, afecta a la esfera psicofísica pero también supone el menoscabo de los bienes y derechos de la personalidad. De abi que los mecanismos de reparación de esta clase de perjuicios resulten tan complejos. En efecto, ni el dinero ni ningún otro bien podrán compensar el daño que provoca la pérdida de un familiar en un accidente o el daño ocasionado a una empresa por la difamación de hechos falsos» ${ }^{33}$.

32 La Audiencia Provincial de Cáceres sí que lo argumentó en su fundamento jurídico quinto, dedicado por entero al análisis de esta cuestión: «Así las cosas, y partiendo de que comportamientos como los enjuiciados, en los términos expuestos de continuidad, intensidad y reiteración, así como el carácter sensible de los datos y la información comprometida han producido un innegable impacto emocional y el consiguiente perjuicio a las víctimas, pero también teniendo en cuenta que no babría llegado a producirse su divulgación a terceros, no existiendo en puridad referentes objetivos para la evaluación de las indemnizaciones, ésta habrá de efectuarse mediante una apreciación global de la trascendencia de los hechos, insistiendo en su repetición y en las circunstancias personales de los perjudicados. Esto es, cuando se trata de fijar la indemnización por los daños morales derivados de la infracción penal, los órganos judiciales no pueden disponer de una prueba sobre la que establecer las bases indemnizatorias aptas para cuantificar con criterios económicos la indemnización procedente, de suerte que las bases para fijar el pretium doloris por los resultados dañosos o consecuencias negativas de indole psicológica, moral o sentimental padecidos por la víctima, las constituyen la propia descripción del hecho punible que ha generado esos efectos, ya que no existe baremo ni referencias preestablecidas que puedan objetivar la evaluación económica de un daño de esa naturaleza, razón por la cual el Tribunal ejerce, efectivamente, una legitima discrecionalidad al decidir el monto de la indemnización por tal concepto (SSTS 821/2003, de 5 de junio; 396/2002, de 1 de marzo y 1751/2002, de 21 de octubre).»

33 CASADO ANDRÉs, B., «El concepto del daño moral. Estudios doctrinales», en RDUNED, n. ${ }^{\circ} 18$, p. $\quad 420, \quad<$ http://e-spacio.uned.es/fez/eserv/bibliuned:RDUNED-2016-18-5070/Concepto_ dano_moral.pdf>, 2016 (28 de enero de 2018). 
Resulta sencillo conectar el caso de estudio con algunos de los principales obstáculos para su valoración, siguiendo a la referida autora: «el establecimiento de un sistema compensatorio justo y equitativo» $\mathrm{y}$ «la subjetividad que impregna el propio concepto y que deja en manos de los juzgadores la determinación del quantum indemnizatorio.» A pesar de ello, debemos en este punto recordar la pobre cantidad indemnizada por cuatro años de intromisión y seguimiento de datos especialmente sensibles (art. 7.3 LOPD, en conexión con el art. 19 del mismo cuerpo legal, en relación al derecho a indemnización): 750 euros en sentencia, una mejora del $25 \%$ respecto a lo solicitado por el Ministerio Fiscal: 600 euros.

Seguramente tanto la Sala como el Ministerio Fiscal son partidarios de evitar la llamada «patrimonialización de los derechos fundamentales». En esta concreta materia, y conectando con las conclusiones de CASADO ANDRÉS, cabe destacar a ABERASTURI GORRIÑO. De acuerdo con el referido autor: «Esta idea respondería sobre todo a la necesidad tantas veces puesta de manifiesto de despatrimonializar los derechos fundamentales. Es cierto que hoy día no cabe discutir sobre si los daños morales derivados de la vulneración de los derechos vinculados a la personalidad son reparables o no. No obstante, la asunción de que estos daños pueden ser compensados mediante una indemnización económica no puede llevar a convertir, como se ba pretendido en ocasiones, estos derechos en mera mercancía cuya vulneración en todo caso merezca indemnización ${ }^{34}$.

Desde mi punto de vista, existe un término medio entre la patrimonialización de los derechos fundamentales y su total falta de consideración. De hecho, nos encontramos ante la vulneración de dos bienes jurídicos diferentes. De un lado, el derecho fundamental a la protección de datos de carácter personal (muy sensibles ex. art. 7.3 LOPD) y la autodeterminación informativa (art. 18.4 CE), cuya indemnización se encuentra legalmente habilitada y prevista en el art. 19 LOPD $^{35}$. Del otro, una vulneración palmaria del derecho a la intimidad y la propia imagen (art. 18.1 CE), cuya indemnización también está normativamen-

34 Aberasturi Gorriño, U., «El derecho a la indemnización en el artículo 19 de la Ley orgánica de Protección de Datos de Carácter Personal», en Revista Aragonesa de Administración Pública, n. ${ }^{\circ} 41-42$, p. 202, <https://dialnet.unirioja.es/descarga/articulo/4486289.pdf>, 2013 (30 de enero de 2018).

35 VÁzQUEZ DE CASTRO, E., «La autonomía del paciente y la protección de datos personales sensibles. Especial referencia a la historia clínica electrónica», en Revista Aranzadi de Derecho y Nuevas Tecnologías, n. ${ }^{\circ}$ 36/2014 parte Estudios jurídicos: «En definitiva, cuando se trata de bistorias clínicas o ficheros especialmente referidos a datos personales sobre la salud el responsable del tratamiento va a ser el Centro Sanitario sin que desparezca la responsabilidad de otros intervinientes». 
te establecida en virtud de la Ley Orgánica 1/1982, de 5 de mayo, de protección civil del derecho al honor, a la intimidad personal y familiar y a la propia imagen, más concretamente en su artículo 9.2.c. Además, el art. 7.4 preceptúa como intromisión ilegítima, en todo caso: «La revelación de datos privados de una persona o familia conocidos a través de la actividad profesional u oficial de quien los revela.» Es cierto que el art. 9.3 supedita en cierto modo la indemnización a la difusión de la información obtenida ${ }^{36}$. Dadas las exigencias del proceso penal, la Audiencia Provincial de Cáceres declaró que no podía inferirse revelación de la información sensible por parte de la acusada. Pero es de vital importancia recalcar que las víctimas se percataron del espionaje durante la tramitación de un procedimiento civil de modificación de medidas en 2014 (hecho que omite totalmente el Tribunal Supremo), a raíz de una pregunta efectuada por la letrada que defendía a la hija de la acusada, lo que constata que la información llegó a un tercero, pero sin que pudiese acreditarse el nexo causal (se atribuyó la transmisión de la información a la hija de la acusada ${ }^{37}$ ). Tal hecho puso en alerta a las víctimas, siendo a la postre el detonante de la acción penal.

Más allá del alcance de la revelación, si ponemos en contexto las pobres cifras citadas (alrededor de 7 euros por intromisión como coste marginal), y la ausencia total de valoración del hecho de ser víctima de un seguimiento prolongado durante cuatro años, todo conduce indefectiblemente a considerar que la indemnización reconocida fue a todas luces insuficiente. Si la compensación por la violación de un derecho fundamental clave como la intimidad es

36 «La existencia de perjuicio se presumirá siempre que se acredite la intromisión ilegítima. La indemnización se extenderá al daño moral, que se valorará atendiendo a las circunstancias del caso y a la gravedad de la lesión efectivamente producida, para lo que se tendrá en cuenta, en su caso, la difusión o audiencia del medio a través del que se haya producido».

37 La Audiencia Provincial de Cáceres lo explica en el fundamento de derecho segundo de su resolución del siguiente modo: «La posibilidad de que la Sra. Bernarda, como anterior pareja del Sr. Martin, tuviera ya información, derivada de su propia relación con éste, acerca de su salud, adicciones y tratamientos que babía seguido - dijo conocer el problema desde 2006 y señaló como una de las razones del cese de su convivencia tal problema-, e igualmente, la adscripción, que era conocida a dicha parte como dijimos, de la profesional que suscribió el informe aportado al CEDEX, sin perjuicio de que dicha Psicóloga también desplegara su actividad en otras áreas del espectro sanitario, no permiten descartar a priori que al margen de las informaciones procedentes de los indebidos accesos a la historia clínica del paciente, se bubiera conocido que éste había acudido a dicho centro de drogodependencias, y la posibilidad de que se le bubiera derivado a él desde cualquier otro servicio, si efectivamente, como se viene diciendo, era sabido que el Sr. Martin estaba sometiéndose a tratamiento para superar sus problemas. Atendiendo a lo expuesto, resulta ciertamente complicado poder asegurar que, a la vista de este único elemento de controversia, pueda concluirse que bubo difusión o revelación de las informaciones indebidamente obtenidas por la acusada y que fuera precisamente ella la que las bubiera becho llegar a conocimiento de terceros.» 
tan insignificante, podría fácilmente caerse en el paralelismo de que dicho derecho no goza de especial relevancia o reconocimiento en la práctica. De ello se derivaría una cierta sensación de vacío o superfluidad incompatible con la naturaleza sistemática de la intimidad, reconocida como derecho fundamental tanto a nivel nacional como comunitario.

\section{c) Obcecación, comportamientos socialmente aceptables y antisociales}

Como ya hemos venido introduciendo sucintamente, observamos que a lo largo de la resolución todos los comportamientos antisociales de la acusada sirven para «abonar» la atenuante aplicada. En palabras de la Sala: «dado que Cirilo era la anterior pareja de la bija de la acusada, a la vez que padre de sus nietos, estando las visitas de los dos bijos habidos con su bija, reguladas por sentencia judicial, la inferencia de falta de simpatía no parece improbable, pero en nada afecta a la comisión delictiva imputada, ni a las atenuantes estimadas, sino más bien, abona la concurrencia de la obcecación.» $\mathrm{Al}$ final, se produce un efecto socialmente indeseable, a modo de regla inversamente proporcional, dado que podría interpretarse que, a más comportamientos antisociales, menor pena, habida cuenta que «abonan» la atenuante de obcecación.

Como es bien sabido, la obcecación es una situación pasional duradera de ofuscación o turbación del ánimo ${ }^{38}$, oscurecedora de las capacidades intelectivas y volitivas del agente, que actúan por ello mermadas, y requiere la existencia previa de estímulos o causas poderosas, no repudiables por las pautas de convivencia social, y procedentes de quien resulta víctima, que determinan causalmente el estado de obcecación ${ }^{39}$. Así lo recuerda también el Alto Tribunal en la sentencia de análisis:

«tales estímulos no ban de ser reprochados por las normas socio-culturales que rigen la convivencia social y deben proceder del precedente comportamiento de la victima, con una relación de causalidad entre los estímulos y el arrebato u obcecación y una conexión temporal, sino inmediatos si próximos, entre la presencia de los estímulos y el surgimiento de la emoción o pasión (SSTS 1110/96 de 20 de diciembre, 1479/99 de 18 de octubre).

38 GONZÁLEZ DE LA TAJADA, I., «Atenuante de arrebato o estado pasional. Diferencia con meros estados de ánimo», en Revista Aranzadi Doctrinal, n. ${ }^{\circ}$ 9/2016 parte Jurisprudencia.

39 En esta línea, sentencias del Tribunal Supremo: 597/98 de 21 de abril; 420/99, de 15 de marzo; 1353/99, de 24 de septiembre; 1802/02, de 4 de noviembre; 2127/02, de 19 de diciembre; 634/05, de 17 de mayo; o 356/08 de 4 de junio. 
Es preciso también que en el entorno social correspondiente no sean tales estímulos repudiados por la norma socio-cultural imperante, lo que significa que la actuación del agente se ha de producir dentro de un cierto sentido ético ya que su conducta y sus estímulos, no pueden ser amparados por el Derecho cuando se apoyan en una actitud antisocial reprobada por la conciencia social imperante, que en esta relación de causa o efecto entre el estímulo desencadenante y la conducta ba de darse una conexión temporal y que cualquier reacción colérica que las que, con frecuencia, acompañan a ciertas acciones delictivas, no basta para la estimación de la atenuante.»

Alejándonos ahora de la perspectiva técnica jurídico-penal, y con los hechos en la mano, lo cierto es que un observador objetivo lego en derecho podría apreciar, con razón, que el efecto producido en el ofendido es de cierta desprotección. No solo debe soportar la violación de su intimidad sistemáticamente durante cuatro años, sino que además debe soportar «iras, insidias e injurias de la acusada» que permiten a la autora rebajar su pena, con muy baja consideración al daño moral sufrido. Ante el estupor que esta lectura «de la calle» puede ocasionar, y siendo un tema susceptible de generar debate, debemos abordar su entendimiento realizando más pedagogía penal. Se trata, evidentemente, de ofensas de distinta naturaleza. Por ello, en puridad, debe desligarse la existencia de un posible delito de injurias (ya que tal extremo no se dirimía en el procedimiento de referencia), del acceso ilegítimo a los historiales clínicos de las víctimas. Por consiguiente, desde el plano técnicojurídico, esta actitud antisocial de la acusada frente a sus víctimas podrá ser reprochable, pero no tiene incidencia en el caso de estudio, apreciación en la que coincidimos totalmente con la Sala.

A continuación se citan los últimos párrafos del fundamento jurídico tercero, donde se motiva la estimación del estímulo y la perturbación necesarias, así como su justificación y origen:

«En autos, todos los requisitos enumerados, concurren con especial intensidad:

- el estímulo es poderoso, el bienestar y seguridad de sus nietos, en el cumplimiento del régimen de visitas, ante los problemas de adicción del padre y los temores de los que pudiera tener su actual esposa; obra 'con el ánimo de proteger a los menores'; estímulo que no solo no contradice norma socio-cultural alguna, sino que conlleva una ponderación positiva, social y normativa; $y$

- la perturbación, procede pues de la 'intensa preocupación por el bienestar de sus nietos cuando se encontraban en compañía de su padre, temiendo por la seguridad de éstos', que deriva y se convierte 'en una verdadera obsesión, que le producía un importante estado de ansiedad'». 
En otras palabras: la cantidad y variedad de comportamientos antisociales de la acusada (y que soportan las víctimas) resulta en el abono de una atenuante, es decir, que paradójicamente sirven para rebajar la pena. Es obvio que se trata de una lectura a contracorriente, que se aleja se los cánones clásicos de justificación de las atenuantes como merma de la antijuridicidad de las conductas tipificadas, pero que no por ello deja de basarse en un resultado real y apreciable. Esto contribuye a la incredulidad no solo de los perjudicados, sino también de otros observadores que aprecian la existencia de una velada impunidad para tales conductas antisociales. Resulta complicado hacer pedagogía penal que explique los fundamentos de la culpa cuando, desde la mera observación, se aprecia un desequilibrio entre los referidos comportamientos y las penas impuestas, en una suerte de relación inversamente proporcional, a la que ya hicimos mención con anterioridad.

\section{IV.3. Intimidad y autodeterminación informativa vs. protección del interés superior del menor: crítica a la ponderación efectuada sobre dos bienes jurídicos dignos de protección}

Como ha constatado nuestro Tribunal Constitucional (en nuestra doctrina, vid. MARTÍNEZ DE PISÓN ${ }^{40}$ ), el art. $18.1 \mathrm{CE}$ garantiza «el secreto sobre nuestra propia esfera de vida personal y, por tanto, veda que sean los terceros, particulares o poderes públicos, quienes decidan cuáles son los contornos de nuestra vida privada» (SSTC 83/2002, de 22 de abril, Ff5, y 99/2002, de 6 de mayo, Ff6). En cuanto al art. $18.4 \mathrm{CE}$, relativo a la autodeterminación informativa, y también vulnerado, la STC 135/2014 de 8 de septiembre, fundamento jurídico quinto, y más recientemente la STC 39/2016 de 3 de marzo declaran que: «el derecho a la protección de datos no es ilimitado, y aunque la Constitución no le imponga expresa-

40 Martínez de Pisón, J., «El derecho a la intimidad: de la configuración inicial a los últimos desarrollos en la jurisprudencia constitucional», en Anuario de Filosofía del Derecho, n. ${ }^{\circ}$ XXXII (enero 2016), pp. 409-430. El referido autor constata la especial importancia de la intimidad y protección de los datos relativos a la salud: «Además, surgen nuevos bienes o intereses ligados a la personalidad que merecen protección. Es el caso de las reclamaciones de protección de los datos personales que se encuentran en ficheros informáticos y que han dado lugar a la libertad informática (art. 18.4 CE), especialmente, relevante en las cuestiones relacionadas con la salud. 4. A su vez, la doctrina del Tribunal Constitucional encuentra un importante acomodo y fundamento en la linea jurisprudencial marcada por el Tribunal Europeo de Derechos Humanos y su interpretación del art. 8 del Convenio Europeo de Derechos Humanos, cuyo art. 8 regula el derecho al respeto a la vida privada y familiar.» (pp. 423-424). 
mente límites específicos, ni remita a los poderes públicos para su determinación como ha becho con otros derechos fundamentales, no cabe duda de que ban de encontrarlos en los restantes derechos fundamentales y bienes jurídicos constitucionalmente protegidos, pues así lo exige el principio de unidad de la Constitución». Como es bien sabido, los Derechos Fundamentales no son ilimitados ${ }^{41}$, y su ejercicio debe cohonestarse con el resto de bienes jurídicos merecedores de protección en nuestro ordenamiento jurídico. En el caso analizado, el Tribunal Supremo contrapone la importancia del «interés superior del menor» frente al derecho a la intimidad y a la autodeterminación informativa.

La resolución de referencia contextualiza constantemente los comportamientos de la acusada dentro del «miedo o preocupación por sus nietos», y pone de relieve la conexión de estos comportamientos con la defensa del interés superior del menor en el fundamento jurídico séptimo. Evidentemente, esto abre una vía importante y peligrosa que afecta directamente a cualquier proceso de familia donde haya menores. Bajo idéntica premisa de «obcecación» y «preocupación por los menores», cabría razonablemente esperar que comportamientos antisociales que repliquen estos patrones obtendrían idéntica consideración en sede penal. Esto introduce de facto una potencial brecha que es susceptible de viciar los procesos de familia. Nótese el hecho de que una atenuante de dos grados, junto con la atenuante de reparación del daño, y unido a bajas indemnizaciones, genera el caldo de cultivo ideal para abusos en nombre del «interés superior del menor», compatible con «ceguedad u ofuscación» (máxime sin necesidad de base patológica) y «sustrato pasional» cuando están los hijos o nietos de por medio.

En el comportamiento desplegado por la acusada, a sabiendas de la gravedad de la intromisión y prevaliéndose de los privilegios anejos a su profesión ${ }^{42}$, encontramos que se ha producido una violación del derecho fundamental a la intimidad, en un ejercicio inadecuado y malinterpretado de «la protección del interés del menor». Evidentemente, ningún ciudadano puede, a título particular, irrogarse tal capacidad. Su obligación será ponerlo en conocimiento de

41 Bello Janeiro, D., «Comentario a la sentencia de 17 de septiembre de 2014», en Cuadernos Civitas de Furisprudencia Civil, n. ${ }^{\circ}$ 98/2015 (sección Sentencias, Resoluciones, Comentarios).

42 Gil Membrado, C., La historia clínica. Deberes del responsable del tratamiento y derechos del paciente, Comares, Granada, 2010, pp. 265 a 267. Concluye la autora este examen sintetizando: «Por el contrario, los profesionales que no tengan encomendado el diagnóstico o tratamiento del paciente concreto, tienen vetado el acceso y en el caso de que trataran la información relativa a un paciente, que no sea propio sino ajeno, dicho acto constituiría un uso ilegítimo de los datos». 
la autoridad policial o del Juzgado de Primera Instancia por vía urgente (art. 13.1 LOPJM), incluso para la adopción de medidas paterno-filiales, situación prevista expresamente en el art. 158.4 CC. Llegado el caso, ante un peligro flagrante e inminente, podría entenderse una acción que vulnerase otras normas del ordenamiento, si de la misma se derivase una actuación que efectivamente produjese de forma causal e inmediata la salvaguarda de la vida o la salud de los menores (o cualquier otro ciudadano).

Pero en el caso de análisis, la acusada iza la bandera de la protección al menor para justificar sus actuaciones y, creemos, este proceder no puede ser convalidado judicialmente, como ha ocurrido en este caso. $\mathrm{Y}$ obtiene el respaldo de la Sala para la estimación de la atenuante en el fundamento jurídico séptimo (además del tercero referido con anterioridad), que certifica con el siguiente tenor literal: «Pero además, en autos, contamos con que los estímulos tan poderosos por los que actuaba, no sólo no contrarían las normas socioculturales, sino que atienden a un bien normativo constitucionalizado como es el interés del menor, y además actúa ante la creencia de un peligro inminente y constante, creencia pues de una causa de justificación, pues es la propia resolución recurrida la que narra, que la acusada actuaba movida por un estado obsesivo que ba terminado afectando a su conducta, desconectándola de los parámetros de la normalidad, funcionando como tal la creencia de que las adicciones del Sr. Cirilo y las que también atribuía a su pareja, como explicó en el plenario, iban a suponer un peligro inminente y constante para sus nietos, temiendo por la seguridad de éstos ante comportamientos desajustados que pudieran protagonizar aquéllos. En el propio relato de hechos probados, se contiene, que el acceso a los datos reservados, lo realizaba con el ánimo de tratar de proteger a dichos menores (sus nietos)». Resulta evidente la sensación de que la línea discursiva de la acusada, insistiendo en proteger a los menores ante un supuesto peligro inminente para los mismos que, recordemos, no consta acreditado que fuese de suficiente entidad como para suspender o modificar el régimen de visitas en sede de medidas paterno-filiales, le ha servido para justificar la comisión de los hechos delictivos y obtener una atenuante muy cualificada.

Formalmente, el Tribunal intenta desvincular esta relación en el último párrafo de los Fundamentos Jurídicos de la sentencia. Afirma que la rebaja se desliga de: «matizaciones en la estimación de los tipos agravados», «error de probibición sobre una causa de justificación», «o de no exigibilidad de otra conducta, cuestiones que restan fuera del objeto del recurso». En su lugar, precisa que se debe a «la ponderación omitida en la motivación de elementos contenidos en la sentencia que revelan además de una menor culpabilidad, mayor que la ponderada y también una relevante menor antijuricidad en los términos expresados, que determinarán una re- 
levante y especial intensidad lógicamente tributaria de la degradación en dos grados». Dicho de otro modo: porque las circunstancias del caso no fueron valoradas adecuadamente por la Audiencia Provincial de Cáceres.

Pues bien, tales circunstancias no pueden ser otras que la tan reiterada «cierta intensidad» de la obcecación, atenuante que pasa de 1 a 2 grados. Sin embargo, la gravedad de la obcecación no viene fundada en material probatorio externo (por ejemplo, informes médicos), sino por el resto de circunstancias a las que va haciendo mención la Sala a lo largo de la resolución (inquina personal, reiteración en la conducta delictiva prolongada en el tiempo, insistencia en las acusaciones de peligro, etc.), de tal suerte que estos hechos no están escindidos del sustrato fáctico-jurídico que genera la atenuante, como pretendía desligar el Alto Tribunal en el párrafo anterior.

Prueba evidente es que la propia Sala afirma en el fundamento jurídico segundo, apartado primero, párrafo quinto: «En el presente caso, ya hemos dicho que la acusada había actuado movida por un estado obsesivo que ha terminado afectando a su conducta, desconectándola de los parámetros de la normalidad, funcionando como tal la creencia de que las adicciones del Sr. Cirilo y las que también atribuía a su pareja, como explicó en el plenario, iban a suponer un peligro inminente y constante para sus nietos, temiendo por la seguridad de éstos ante comportamientos desajustados que pudieran protagonizar aquéllos. Entendemos que tal situación es la que se ha dado en el presente caso y creemos que la circunstancia atenuante indicada será aplicable, revistiendo además una cierta intensidad.» En otras palabras, estos comportamientos son los que otorgan «cierta intensidad» a la atenuante aplicada. Por consiguiente, esta afirmación revela claramente la influencia de la obcecación familiar a la hora de apreciar la intensidad de la atenuante y, con ello, su influjo en el fallo alcanzado.

Producto de todo lo anterior, lo cierto es que la justificación de la acusada de velar «por la protección del interés de los menores» acaba por servir de abono para construir su propia atenuante. El propio Tribunal lo certifica en su fundamento de derecho séptimo:

«Pero además, en autos, contamos con que los estímulos tan poderosos por los que actuaba, no sólo no contrarían las normas socioculturales, sino que atienden a un bien normativo constitucionalizado como es el interés del menor, y además actúa ante la creencia de un peligro inminente y constante, creencia pues de una causa de justificación, pues es la propia resolución recurrida la que narra, que la acusada actuaba movida por un estado obsesivo que ba terminado afectando a su conducta, desconectándola de los parámetros de la normalidad, funcionando como tal la creen- 
cia de que las adicciones del Sr. Cirilo y las que también atribuía a su pareja, como explicó en el plenario, iban a suponer un peligro inminente y constante para sus nietos, temiendo por la seguridad de éstos ante comportamientos desajustados que pudieran protagonizar aquéllos. En el propio relato de hechos probados, se contiene, que el acceso a los datos reservados, lo realizaba con el ánimo de tratar de proteger a dichos menores (sus nietos).»

Debemos recordar en este punto que la Ley Orgánica 1/1996, de 15 de enero, de Protección Jurídica del Menor establece taxativamente en su art. 13.1: «Toda persona o autoridad y especialmente aquellos que por su profesión o función detecten una situación de maltrato, de riesgo o de posible desamparo de un menor, lo comunicarán a la autoridad o sus agentes más próximos, sin perjuicio de prestarle el auxilio inmediato que precise». Todo lo que exceda del auxilio inmediato, supone una trasgresión de la norma. Serán estos agentes quienes, en aplicación del art. 2.1 de la LOPJM, se encarguen de aplicar el concepto de interés superior del menor, de acuerdo con los parámetros contenidos en el apartado $2 .^{\circ}$ de dicho precepto $^{43}$. Recordemos en este punto que el juez civil que conocía de las relaciones paterno-filiales tras la ruptura del matrimonio, no consta que adoptase ninguna medida en el régimen de visitas a raíz de los hechos esgrimidos por la acusada. O bien se puso en su conocimiento y no se consideró peligroso al padre de los menores, o bien no se puso en su conocimiento y la acusada se extralimitó de forma sostenida en el tiempo.

43 A efectos de la interpretación y aplicación en cada caso del interés superior del menor, se tendrán en cuenta los siguientes criterios generales, sin perjuicio de los establecidos en la legislación específica aplicable, así como de aquellos otros que puedan estimarse adecuados atendiendo a las circunstancias concretas del supuesto:

a) La protección del derecho a la vida, supervivencia y desarrollo del menor y la satisfacción de sus necesidades básicas, tanto materiales, físicas y educativas como emocionales y afectivas.

b) La consideración de los deseos, sentimientos y opiniones del menor, así como su derecho a participar progresivamente, en función de su edad, madurez, desarrollo y evolución personal, en el proceso de determinación de su interés superior.

c) La conveniencia de que su vida y desarrollo tenga lugar en un entorno familiar adecuado y libre de violencia. Se priorizará la permanencia en su familia de origen y se preservará el mantenimiento de sus relaciones familiares, siempre que sea posible y positivo para el menor. En caso de acordarse una medida de protección, se priorizará el acogimiento familiar frente al residencial. Cuando el menor hubiera sido separado de su núcleo familiar, se valorarán las posibilidades y conveniencia de su retorno, teniendo en cuenta la evolución de la familia desde que se adoptó la medida protectora y primando siempre el interés y las necesidades del menor sobre las de la familia.

d) La preservación de la identidad, cultura, religión, convicciones, orientación e identidad sexual o idioma del menor, así como la no discriminación del mismo por éstas o cualesquiera otras condiciones, incluida la discapacidad, garantizando el desarrollo armónico de su personalidad. 
En definitiva, se ha producido una importante indefensión a las víctimas y su derecho fundamental a la intimidad, paupérrimamente valorado, mientras que la sentencia pone en valor la actitud de la acusada para explicar la conducta delictiva (durante cuatro años), defendida como el «ánimo de tratar de proteger a dichos menores», constituyendo a fin de cuentas el pilar sobre el que se construye la atenuante aplicada. En síntesis, cabría afirmar que el desequilibrio en la ponderación de ambos bienes jurídicos es doble. En primer lugar, podría argüirse fácilmente que las víctimas merecían mayor compensación, habida cuenta la sensibilidad de los datos, la afectación a su intimidad, y la extensión del seguimiento en el tiempo. En segundo lugar, que el peso de la autoproclamación de la acusada como defensora del interés de los menores ha sido valorado de modo desproporcionadamente favorable, sirviendo para rebajar la pena de forma sustancial, que pasa de 3 años y 8 meses a 2 años de privación de libertad. Gracias a ello, podría beneficiarse de la suspensión de la pena que prevé el art. $80 \mathrm{CP}^{44}$.

\section{Conclusiones}

Resulta novedosa y llamativa la sentencia de análisis, a la vista del celo que durante la presente década venía mostrando el Tribunal Supremo en cuanto al acceso ilícito a datos médicos (considerados «núcleo duro de la intimidad»), tal y

44 Sobre los efectos de esta figura en el ordenamiento penal, vale la pena citar a Cid Moliné: «Un análisis de la suspensión de la pena desde el punto de vista utilitarista, y por tanto atendiendo a sus beneficios y a sus costes, muestra que los posibles beneficios de la suspensión de la pena —la evitación del sufrimiento de la pena de prisión para las personas y el aborro económico del encarcelamiento para el estado- deben ser comparados con sus costes. Los costes —o, en otra terminología, las objeciones a la suspensión de la pena-podrían inchuir, en primer lugar, una reducción del nivel de prevención general negativa o de educación moral en comparación con castigos más severos (...)». CID MOLINÉ, J., «La suspensión de la pena en España: descarcelación y reincidencia», Revista de Derecho penal y criminología, n. ${ }^{\circ} 15$, pp. 227 y $236<$ http://e-spacio.uned.es/fez/eserv.php?pid=bibliuned:revistaDerechoPenalyCrim inologia-2005-15-5070\&dsID=Documento.pdf>, 2005 (15 de abril de 2018).

A mi juicio, el presente caso posiblemente es un fiel reflejo de esa reducción del nivel de prevención general negativa o de educación moral que, con acierto, expone el citado autor. Ello no supone una crítica al sistema de suspensión de ejecución de las penas propiamente dicho, cuyo valor resulta incuestionable (también CID MOLINÉ en esta línea: «la suspensión ha supuesto un beneficio indudable, por haber evitado la experiencia del encarcelamiento a un importantísimo número de personas»); sino que sirve para abrir un interrogante en materia de violación de la intimidad, protección de datos y secreto médico: ¿comienza aquí una nueva etapa, menos severa, en la jurisprudencia del Tribunal Supremo en materia de trasgresiones de la intimidad, el secreto médico y la protección de datos sanitarios? 
como hemos puesto de relieve. Máximas de experiencia práctica invitan a pensar que no se trata tanto de un giro en la tendencia habitual de garantizar un alto estándar de protección a un bien jurídico de máxima importancia como es la intimidad. Más bien, podríamos encontrarnos ante un ejercicio de mano izquierda para con la acusada, utilizando los preceptos legales que habilitan al Tribunal (120.3 CE y $72 \mathrm{CP}$ ) para apreciar libremente el grado de la atenuante de obcecación en uno o dos grados. Esta conclusión se sostiene, no solo por las sutiles inconsistencias que se advierten en la argumentación de la sentencia, sino también por el encaje milimétrico de la nueva condena de pena privativa de libertad dentro del límite de 2 años previsto en el art. $80 \mathrm{CP}$, que permite disfrutar del beneficio de la suspensión de la misma.

Ahora bien, aun pudiendo entenderse los motivos de orden ético-moral que explicarían la rebaja de la condena de prisión para la enfermera acusada, en todo caso ha quedado profundamente infravalorada la indemnización reconocida a las víctimas. En este punto no podemos estar de acuerdo con la sentencia analizada, ya que la obcecación podrá ser un estado alterado modificativo de la responsabilidad penal, pero en ningún caso de la civil. Es cierto que los tribunales carecen de instrumentos legales sólidos que les permitan estandarizar u homogeneizar el cálculo de los daños morales (de acuerdo con las palabras de la Sala: «siempre de difícil cuantificación») en base a unos parámetros prestablecidos. Pero ello no es un obstáculo que permita prescindir de todo razonamiento al respecto. Cuantías tan bajas no sirven a ninguna finalidad: ni reparan de forma satisfactoria a las víctimas, ni generan un efecto disuasorio que desincentive y prevenga la comisión de esta clase de infracciones.

En el plano penal, queda por ver la influencia de esta sentencia en futuras resoluciones, en particular en lo que respecta a la apreciación de la atenuante de obcecación, cuando esta se genere con motivo de la protección de los menores. Resulta inaceptable que pueda utilizarse a modo de escudo tras el que parapetarse para reducir muy significativamente el alcance de una eventual condena penal, tan solo a cambio de sostenerlo de manera obstinada y pertinaz, y siempre distorsionado como defensa de la familia. Máxime, advirtiendo que dentro de ella, los menores son los sujetos más merecedores de protección, siendo el bienestar de los hijos y nietos posiblemente el «estímulo emocional» de mayor «impacto» posible, dando pie a una justificación demasiado prona.

Es cierto que la protección del interés del menor es un bien jurídico de altísima prioridad en la sociedad contemporánea, y que tiene un excelente soporte normativo en el ordenamiento jurídico. Pero debe cohonestarse con la existencia y ejercicio del resto de derechos amparados por nuestro sistema. 
Creemos que la única respuesta admisible a la preocupación o turbación por el estado de los menores es la puesta en conocimiento de la autoridad de los hechos potencialmente peligrosos; ya sean las fuerzas y cuerpos de seguridad del Estado, ya sea en conocimiento del juez de guardia, o del juez de primera instancia que haya tomado medidas relativas a los menores implicados, dependiendo de la naturaleza de la amenaza que se cierna sobre ellos. Y en todo caso, podrán admitirse las eximentes del art. $20 \mathrm{CP}$ para situaciones muy extraordinarias y tasadas, siempre con carácter excepcional. 